\title{
Mass transfer in the bath reactor of the adsorption process of 1,2-dichloropropane from aqueous solution onto the activated carbon
}

\author{
Robert Pełech \\ Szczecin University of Technology, Institute of Chemical Organic Technology, ul. Pulaskiego 10, 70-322 Szczecin, Poland \\ e-mail: Robert.Pelech@ps.pl, tel. (+48 91) 4494016 \\ A pseudo-second order rate equation describing the kinetics of the adsorption of 1,2-dichloropropane from \\ aqueous solution onto the activated carbon at different initial concentrations, adsorbent dose, temperature, \\ particle diameter and the rate of stirring have been developed. The rate constant was calculated. The rate \\ constant correlation in a good mixing conditions was described as a function of the temperature.
}

Keywords: 1,2-dichloropropane, activated carbon, adsorption, kinetic, waste.

Presented at VII Conference Wasteless Technologies and Waste Management in Chemical Industry and Agriculture, Międzyzdroje, 12 - 15 June, 2007.

\section{INTRODUCTION}

Wastewaters containing 1,2-dichloropropane (DCP) are discharged in a large amount from the production plant of propylene oxide. Because of their significant resistance to biodegradation and their carcinogenic and mutagenic properties, their removal is purposeful. A high degree of purification can be achieved by using the adsorption method on the activated carbons ${ }^{1-3}$.

The adsorption processes are usually carried out on an industrial scale in the columns packed with adsorbents or bath reactors. The fundamental information concerning the process is achieved experimentally by the investigation of the systems with a constant volume of a treated liquid. The equilibrium and the major kinetic parameters relating to the mass transfer can be determined on the basis of these studies ${ }^{4}$.

The rate of the adsorption process is determined by the diffusion or convection in the solution, the diffusion across the boundary layer surrounding the particle, the intraparticle diffusion and the diffusion in the pores volume. The diffusion and convection in the solution have no influence on the process rate in the systems where a good mixing of the solution was ensured. Diffusion through a film takes place at the initial stage of the process, then it transforms into the intraparticle diffusion ${ }^{5}$.

Depending on the system and the hydrodynamic conditions, the external mass transfer coefficient and the intraparticle diffusion or one kinetic coefficient crucial for the rate of the mass transfer are taken into consideration.

In order to examine the mechanism of the adsorption process such as mass transfer and chemical reaction, several kinetic models are used to test the experimental data. The large number and array of different functional groups on the activated carbon surface imply that there are many types of adsorbent-solute interactions. Thus, any kinetics or mass transfer representation is likely to be global. From the system design viewpoint, a lumped analysis of the adsorption rates is thus sufficient for the practical operation.

A simple kinetic analysis of adsorption is the pseudofirst-order equation ${ }^{6,7}$,

$\frac{d a}{d t}=k\left(a^{*}-a\right)$
Where: $a$ - adsorption amount at the time moment $(\mathrm{mg} / \mathrm{g}), a^{*}-$ equilibrium adsorption amount $(\mathrm{mg} / \mathrm{g})$, $k$ - constant rate $(1 / \mathrm{min}), t$ - time $(\mathrm{min})$.

The values of $a^{*}$ must be obtained independently from the equilibrium experiments.

After the definite integration, by applying the initial conditions: $a=0$ at $t=0$, Eq. (1) becomes

$\ln \left(a^{*}-a\right)=\ln \left(a^{*}\right)-k t$

On the other hand, a pseudo-second-order equation based on the adsorption capacity may by expressed in the form

$\frac{d a}{d t}=k\left(a^{*}-a\right)^{2}$

Integrating Eq. (3) and applying the initial conditions, we arrive at

$a=a^{*} \frac{k t}{1+k t}$

and a linear form

$\frac{a}{a^{*}-a}=k t$

\section{EXPERIMENTAL}

\section{Adsorption method}

The sorption of DCP onto the activated carbon was studied by the bath experiments. The examined factors were: the initial DCP concentration, the activated carbon dose, the particle diameter, the mixing rate and the temperature.

All the tests were conducted in capped flasks $\left(240 \mathrm{~cm}^{3}\right)$, by proportioning the DCP stock solution to the activated carbon suspension and mixing in a shaker. The samples were withdrawn at the suitable time intervals and analyzed.

\section{Analytical method}

The concentration of the studied compound was determined chromatographically on a Thermoquest GC $8000^{\text {Top }}$ instrument with a flame ionization detector (FID). The determinations were carried out isothermally at the temperature $100^{\circ} \mathrm{C}$. A capillary column DB-WAX $(\mathrm{J} \& \mathrm{~W})$ $30 \mathrm{~m} \times 0,5 \mathrm{~mm} \times 0,5 \mathrm{~mm}$ was used. 


\section{Materials}

The adsorbent used in these studies was the activated carbon of the DTO type supplied by GRYFSKAND SA (Poland). The adsorbent was sieved into several discrete particle size ranges. The $0.91-0.63 ; 0.4-0.63$ and 0,40 $-0,25 \mathrm{~mm}$ size ranges of the activated carbon were used in these studies. The sieved activated carbon was washed by distilled water to remove fines and then was dried in an oven for $24 \mathrm{~h}$ at $110^{\circ} \mathrm{C}$. The carbon particles were assumed to be spheres having a diameter given by the arithmetic mean value between the respective mesh size (average particle diameters $d_{z}$ were $0.77,0.53$ and 0.33 $\mathrm{mm})$. The properties of the DTO activated carbon are presented in Table 1.1,2-dichloropropane (>99\%) used in these studies was taken from Fluka, A.G.

Table 1. The properties of the DTO activated carbon

\begin{tabular}{|l|c|}
\hline Bulk density $\left(\mathrm{g} / \mathrm{dm}^{3}\right)$ & 400 \\
\hline Apparent density $\left(\mathrm{g}^{\prime} \mathrm{dm}^{3}\right)$ & 860 \\
\hline Total surface $\left(\mathrm{N}_{2}\right.$ BET method $)\left(\mathrm{m}^{2} / \mathrm{g}\right)$ & 943 \\
\hline Pore volume $\left(\mathrm{cm}^{3} \mathrm{~g}^{-1}\right)$ & 0.53 \\
\hline Pore volume $<1.5 \mathrm{~nm}\left(\mathrm{~cm}^{3} / \mathrm{g}\right)$ & 0.25 \\
\hline Porosity & 0.45 \\
\hline
\end{tabular}

\section{RESULTS}

Fig. 1. shows the examples of the DCP kinetic curve onto the DTO activated carbon from aqueous solution. The first-order reaction model was used to check all the results but the correlation coefficient was not high. However, the rate law for a pseudo-second order could be fixed with the very high correlation coefficient. The sorption of DCP onto the activated carbon could be the pseudo-second order process rather than the first-order one.

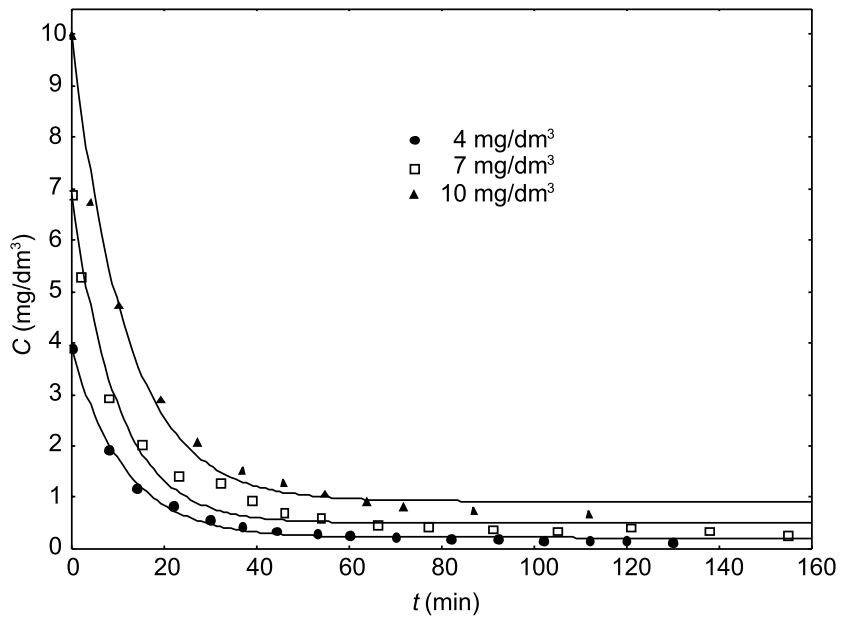

Figure 1. Kinetic curves of the DCP adsorption

\section{Effect of the initial DCP concentration}

Fig. 2 shows kinetic curves in a linear form for three different initial concentrations of DCP. According to Fig. 2 in the examined range of the initial concentrations (4$10 \mathrm{mg} / \mathrm{dm}^{3}$ ), the concentration does not affect the DCP adsorption kinetics in an essential way. For those values of the adsorbates initial concentrations, the duration needed to obtain the equilibrium state is similar and equals about 90 minutes.



Figure 2. Kinetic curves of adsorption for a various initial concentration

\section{Effect of the adsorbent dose}

Fig. 3 shows kinetic curves in a linear form for three different adsorbent doses. It has been observed that the influence of the carbon mass is consistent with the expectations, the increase of the process rate, together with the increase of carbon amount. The rate increase is proportional to the adsorbent concentration, and what follows, to the surface area of the mass transfer. Moreover, in the system where there are more grains, the turbulence is higher and it is possible that in the result of the interstitial shearing, the boundary layer is reduced in a certain range and the molecules of the adsorbate penetrate to surface of the grains easier and faster.

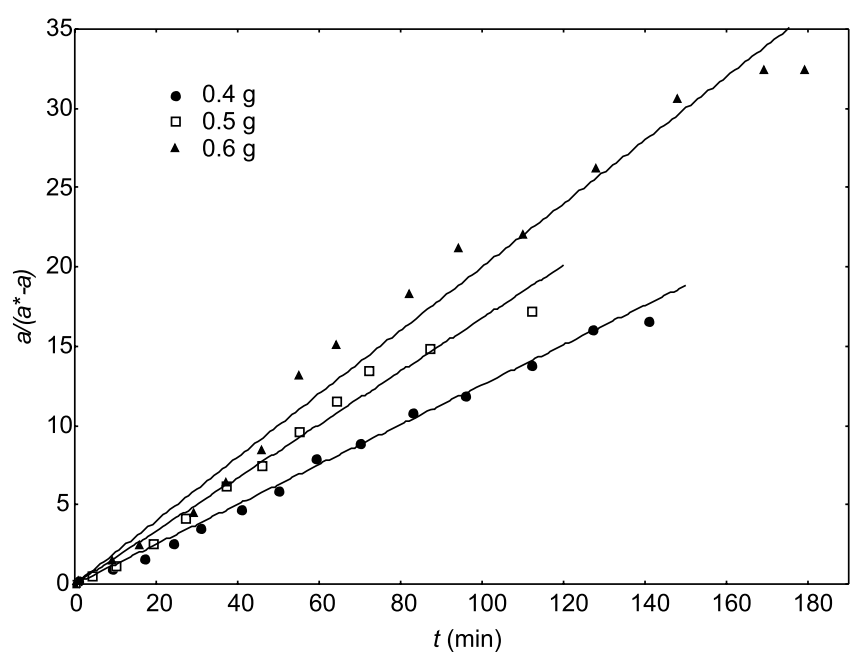

Figure 3. Kinetic curves of adsorption for a various adsorbent dose

\section{Effect of the particle diameter}

Fig. 4 shows kinetic curves in a linear form for three different diameters of the adsorbent particles. Along with the reduction of the particle diameter, the rate of the process increased. The rate is proportional to the increase of the surface area of the mass transfer between the adsorbent and the bulk solution. Such action is also confirmed by the effect caused by the increase of the adsorbent mass. 




Figure 4. Kinetic curves of adsorption for a various particle diameter of the activated carbon

\section{Effect of the mixing rate}

Fig. 5 shows kinetic curves in a linear form for three different mixing rates. With the mixing rate of 200 cycles per minute (cpm) the time needed to obtain the adsorption equilibrium state equals $360 \mathrm{~min}$. The rate of establishing the adsorption equilibrium for 250 and $300 \mathrm{cpm}$ equals about $90 \mathrm{~min}$. Besides, the constant rates determined under such conditions are comparable. It mentions a good mixing of the solution and no influence of external diffusion on the adsorption process.

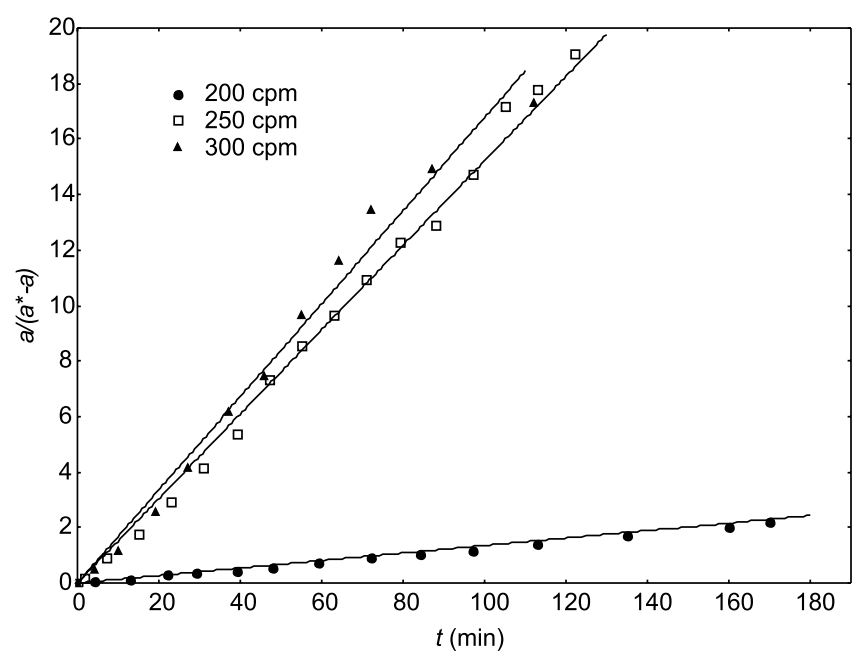

Figure 5. Kinetic curves of adsorption for a various mixing rate

\section{Effect of the temperature}

Fig. 6 shows kinetic curves in a linear form for three different temperatures. In a range of the temperature $293 \mathrm{~K}$ to $313 \mathrm{~K}$ the rate of adsorption of the examined compounds increases. At the temperature of $313 \mathrm{~K}$ almost a double increase of the adsorption coefficient rate was noted, in comparison with the values obtained at the temperature of $293 \mathrm{~K}$.

\section{DISCUSSION}

In Table 2 the determined constant rate $(k)$ for particular processes and the values of the DCP molecular diffusion coefficient in water are presented. The molecular

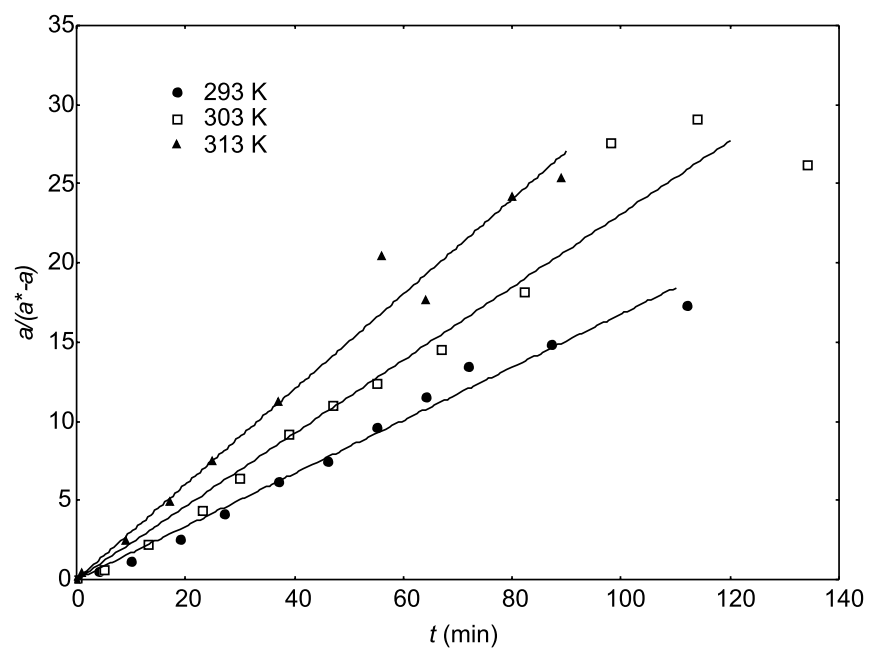

Figure 6. Kinetic curves of adsorption for a various temperature

diffusion coefficients were calculated by the Wilke-Chang method $^{8}$.

It was found that $k$ parameter depends on the contact surface area and on the DCP molecular diffusion coefficient in water in a linear way. The linear dependence of $\mathrm{k}$ can be described by the equation below:

$k=k_{0} D S$

where: $k_{0}$ - constant rate in the temperature of $293 \mathrm{~K}$ and for the surface area of the mass transfer equals $1 \mathrm{dm}^{2}(1 / \mathrm{min}), S$ - surface area of the mass transfer (dm2).

The surface area of the mass transfer is defined as:

$S=m \alpha$

where: $\alpha$ - specific particle area $\left(\mathrm{dm}^{2} / \mathrm{g}\right), m$ - adsorbent mass $(\mathrm{g})$.

The specific particle area was defined as:

$\alpha=\frac{A_{z}}{m_{z}}=\frac{\pi d^{2}}{\frac{\pi}{6} d^{3} \rho}=\frac{6}{\rho d}$

where: $\rho$ - apparent density $\left(\mathrm{g} / \mathrm{dm}^{3}\right), A_{z}$ - particle area $\left(\mathrm{dm}^{2}\right), d$ - particle diameter $(\mathrm{dm}), m_{z}-$ particle mass $(\mathrm{g})$.

According to the Wilke-Chang equation, the molecular diffusion coefficient depends only on the temperature for a given system.

Table 2. The constant rates of the DCP adsorption

\begin{tabular}{|c|c|c|c|c|}
\hline$m$ & $D$ & $k$ & $k_{0} \cdot 10^{-10}$ & $\sigma$ \\
\hline $\mathrm{g}$ & $\mathrm{dm}^{2} / \mathrm{min}$ & $1 / \mathrm{min}$ & $1 / \min$ & $\%$ \\
\hline 0.4 & \multirow{17}{*}{$5.016 \cdot 10^{-10}$} & 0.126 & 0.0476 & 7.9 \\
\hline 0.5 & & 0.168 & 0.0508 & 1.0 \\
\hline \multirow{2}{*}{\multicolumn{4}{|c|}{$\begin{array}{l}0.6 \\
C_{0}, \mathrm{mg} / \mathrm{dm}^{3}\end{array}$}} & 1.6 \\
\hline & & & & \\
\hline 4 & & 0.170 & 0.0515 & 0.4 \\
\hline 7 & & 0.172 & 0.0522 & 1.6 \\
\hline 10 & & 0.168 & 0.0508 & 1.0 \\
\hline \multicolumn{4}{|l|}{$d, \mathrm{~mm}$} & \\
\hline 0.37 & & 0.251 & 0.0531 & 3.4 \\
\hline 0.53 & & 0.168 & 0.0508 & 1.0 \\
\hline 0.70 & & 0.141 & 0.0562 & 8.7 \\
\hline \multicolumn{4}{|l|}{$\mathrm{cpm}, 1 / \mathrm{min}$} & \\
\hline 200 & & 0.014 & 0.0041 & - \\
\hline 250 & & 0.155 & 0.0470 & 9.1 \\
\hline 300 & & 0.168 & 0.0508 & 1.0 \\
\hline \multicolumn{4}{|l|}{$T, \mathrm{~K}$} & \\
\hline 293 & & 0.168 & 0.0508 & 1.0 \\
\hline 303 & $6.710 \cdot 10^{-10}$ & 0.231 & 0.0523 & 1.9 \\
\hline 313 & $8.453 \cdot 10^{-10}$ & 0.301 & 0.0540 & 5.0 \\
\hline & of $K_{0}$ & & 0.0513 & 3.2 \\
\hline
\end{tabular}


Equation 6 allows to define the constant rate of the DCP adsorption onto the DTO activated carbon under the conditions of a good mixing for any temperature.

In Table 2 the relative deviation $\sigma$ between the defined average $k_{0}$ and the values for the particular measurements was presented.

$\sigma=\frac{\left|k_{0}-\overline{k_{0}}\right|}{k_{0}} \cdot 100 \%$

where: $\overline{k_{0}}$ - average values of $k_{0}(1 / \mathrm{min})$.

The mean value of the deviation equals $3.2 \%$ which proves good compatibility of equation 7 with the experimental data.

\section{CONCLUSION}

The DCP adsorption process from aqueous solution in a shaker onto the DTO activated carbon is described well by the model of the pseudo-second order reaction. The rate constant correlation under good mixing conditions was described as a function of the temperature. In the system with a good mixing the equilibrium is established no longer than 90min., irrespective of the rest of the parameters.

\section{LITERATURE CITED}

(1) Milchert E., Goc W., Pełech R.: Adsorption of $\mathrm{CCl}_{4}$ from aqueous solution on activated carbons, Adsorpt. Sci. Technol. 2000, 18, $823-837$.

(2) Pełech R., Bembnowska A., Milchert E.: Recovery of carbon tetrachloride from wastewater, Polish. J. Chem. Technol. 2001, 3, 17 - 19.

(3) Bembnowska A., Pełech R., Milchert E.: Adsorption from aqueous solutions of chlorinated organic compounds onto activated carbons. J. Colloid Interf. Sci. 2003, 256, 276 $-282$.

(4) Pełech R., Milchert E., Wróbel R.: Adsorption dynamics of chlorinated hydrocarbons from multi-component aqueous solution onto activated carbon. J. Hazard. Mater. 2006, 137, 1479 - 1487.

(5) Pełech R., Bembnowska A., Milchert E.: Kinetics of adsorption of hydrocarbon chloro-derivatives from seven component aqueous solution onto a thin layer of DTO activated carbon, J. Colloid Interf. Sci. 2005, 290, 83 - 90.

(6) Ho Y., McKay G.: The kinetics of sorption of divalent metal ions onto sphangnum moss peat. Wat. Res. 2000, 34, $735-745$.

(7) Mall I., Srivastava V., Agarwal N.: Removal of Orange-G and Methyl Violet dyes by adsorption onto bagasse fly ash - kinetic study and equilibrium isotherm analyses. Dyes Pigments. 2006, 69, $210-223$.

(8) Wilke C., Chang P.: Estimation of diffusion coefficients. A.I.Ch.E J. 1955, 1, $264-270$. 